\title{
HUBUNGAN PENGETAHUAN DAN SIKAP DENGAN UPAYA PENCEGAHAN STROKE PADA PASIEN HIPERTENSI DI RUANGAN POLI SARAF RSUD KOTA KOTAMOBAGU
}

\author{
Grace Irene Viodyta Watung \\ Dosen Keperawatan Institut Kesehatan dan Teknologi Graha Medika Kotamobagu \\ Alamat Korespondensi Author: sister.gracewatung@gmail.com
}

\begin{abstract}
Abstrak
Stroke adalah putusnya aliran darah ke otak, umumnya terjadi akibat pecahnya pembuluh darah ke otak atau tersumbatnya pembuluh darah sehingga pasokan nutrisi dan oksigen ke otak berkurang. Stroke menyebabkan gangguan fisik atau disabilitas. Studi melaporkan bahwa dalam 20 tahun terakhir terlihat peningkatan beban stroke di beberapa Negara eropa sebesar 1,1 juta pertahun pada tahun 2000 menjadi 1,5 juta pertahun pada tahun pada tahun 2025. Upaya pencegahan stroke juga di pengaruhi oleh pengetahuan dan sikap penderita stroke. Penelitian ini menggunakan metode deskritif analitik dengan pendekatan cross sectional. Total populasi 30 pasien hipertensi derajat II sampel juga diambil total populasi sebanyak 30 pasien. Analisis data menggunakan uji Chi Square.Hasil:Terdapat hubungan pengetahuan dengan upaya pencegahan stroke pada pasien hipertensi, yaitu di peroleh nilai $\mathrm{P}=0,000$ dimana nilai $\mathrm{p}$ lebih kecil dari $\mathrm{p}(0,05)$. Terdapat hubungan sikap dengan upaya pencegahan stroke pada pasien hipertensi dengan nilai $\mathrm{p}=0.000$. Sebagai saran: untuk tempat penelitian diharapkan dapat memberikan bahan masukan untuk meningkatkan pelayanan kesehatan khususnya pasien hipertensi yang beresiko tinggi terkena stroke. Untuk penelitian selanjutnya diharapkan penelitian lebih baik lagi agar pengetahuan pasien tentang hubungan pengetahuan pecegahan stroke pada pasien hipertensi di ruangan poli saraf RSUD Kota Kotamobagu lebih baik lagi. Bagi petugas kesehtan di Poli Saraf agar giat memberikan penyuluhan kesehatn tentang bahaya dan pencegahan strok.
\end{abstract}

Kata Kunci: Pengetahuan, Sikap, Stroke, Pasien Hipertensi.

\begin{abstract}
Stroke is a cut in blood flow to the brain, generally occurs due to rupture of blood vessels to the brain or blockage of blood vessels so that the supply of nutrients and oxygen to the brain is reduced. Stroke causes physical impairment or disability. The study reports that in the last 20 years there has been an increase in the burden of stroke in several European countries by 1.1 million per year in 2000 to 1.5 million per year in 2025. Stroke prevention influenced by the knowledge and attitudes of stroke sufferers. This research uses cross sectional approach. The total population of 30 patients with grade II hypertension was also taken as a total population of 30 patients. Data analysis using Chi Square test. Results: There is a relationship between knowledge and efforts to prevent stroke in hypertensive patients, which is the value of $\mathrm{P}=0.000$ where the $\mathrm{p}$ value is less than $\mathrm{p}(0.05)$. There is a relationship between attitude and stroke prevention efforts in hypertensive patients with a value of $p=0.000$. As a suggestion: the research site is expected to provide input to improve health services, especially hypertensive patients who are at high risk of stroke. For further research, it is hoped that the research will be better so that the patient's knowledge about the relationship between the knowledge of stroke prevention in hypertensive patients is even better. For health workers, they should be active in providing health education about the dangers and prevention of stroke.
\end{abstract}

Keywords: Knowledge, Attitude, Stroke, Hypertension Patients 


\section{PENDAHULUAN}

\begin{tabular}{|c|}
\hline 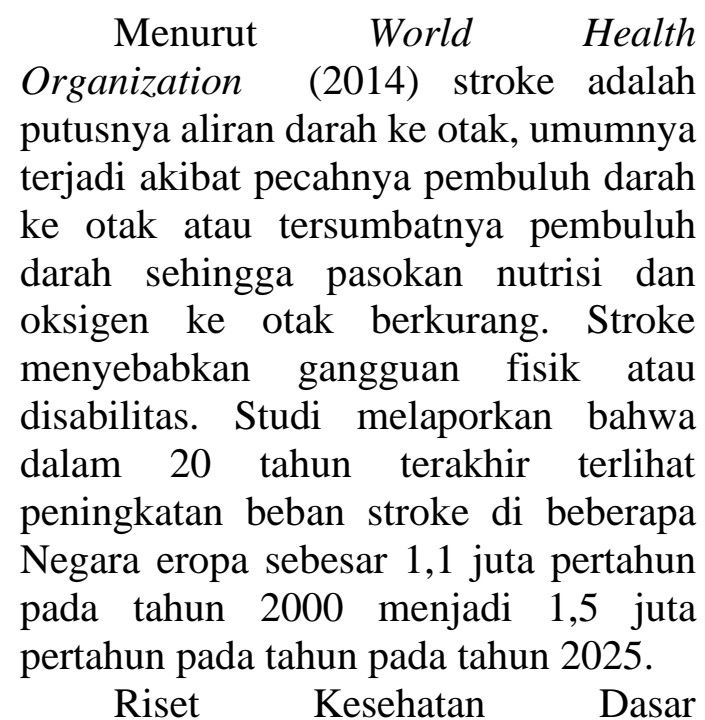 \\
\hline
\end{tabular}
(RISKESDES) 2018 mencatat, angka penderita Penyakit Tak Menular ( PTM ) mengalami peningkatan. Salah satunya adalah stroke yang meningkat selama lima tahun terakhir, Menteri kesehatan RI Nila Farid Moeloek mengatakan, pencegahan sangat penting untuk menurunkan PTM (Penyakit Tidak Menular), termasuk stroke di Indonesia. Perubahan ke arah gaya hidup sehat, kata dia, menjadi salah satu pencegahan untuk PTM (Penyakit Tidak Menular) . Di Indonesia berdasarkan sample registration system (SRM) pada 2014, stroke masih jadi sebab kematian tertinggi di kategorikan penyakit tidak menular dengan angka 21,1 persen. Sedangkan di dunia stroke jadi penyebab kematian tertinggi kedua, dan penyebab kecatatan ketiga.

Prevelensi penyakit stroke tertinggi, berada di provinsi Sulawesi utara yaitu 10,8 per mil, Yogyakarta 10,3 per mil, Bangka Belitung 9,7 per mil,dan DKI Jakarta 9,7 per mil, "prevelensi penderita stroke cenderung lebih tinggi pada masyarakat dengan pendidikan rendah dan masyarakat yang tinggal di perkotaan," ujar nafsiah dalam sambutannya di peresmian Rumah sakit pusat otak, nasional di Jakarta timur.
Berdasarkan data dari dinas kesehatan Kota Manado yang di muat pada manado post online, yaitu dari tahun 2014-Agustus 2016 tercatat bahwa penyakit tertinggi kedua yang di derita oleh warga manado yaitu hipertensi dengan jumlah 11.228 jiwa. Penyakit hipertensi ini yang menigkatkan munculnya penyakit stroke. Pada sebagian besar kasus stroke menunjukkan bahwa penyakit stroke terjadi terjadi dari akumulasi pola hidup dan kebiasaan hidup sehari sehari. Melihat pola gaya hidup orang manado yang pola makannya kurang baik dengan sering mengonsumsi daging. Jumlah konsumsi daging di kota manado yang tinggi adalah penyebab utama hipertensi sehingga menyebabkan stroke.

Berdasarkan data awal yang di dapatkan di RSUD Kota kotamobagu pada tanggal 4 maret 2020 terdapat 215 pasien yang mengalami stroke dengan penyakit hipertensi 1 bulan terakhir yaitu di bulan Februari. Penelitian yang dilakukan oleh (Abdul, Damanik, \& Imawati, 2016) menyatakan bahwa terdapat hubungan antara pemahaman penderita hipertensi dengan perilaku pencegahan stroke. ketidaktahuan responden terhadap penyakit stroke, sehingga pemahaman untuk melakukan perilaku pencegahan stroke pada penderita hipertensi juga buruk demikian sebaliknya.

Terdapat hubungan pengetahuan pasien penderita hipertensi terhadap sikap dalam pencegahan stroke di RSUD Arifin Achmad merupakan hasil penelitian yang dinyatakan oleh Tingkat pendidikan akan mempengaruhi cara berpikir dalam penerimaan penyuluhan dan cara pemberantasan yang dilakukan. Tingkat pendidikan berpengaruh pada tingkat pengetahuan, pengetahuan kesehatan akan berpengaruh kepada sikap sebagai hasil 
jangka menengah dari pendidikan kesehatan, selanjutnya sikap kesehatan akan berpengaruh pada meningkatnya indikator kesehatan masyarakat sebagai hasil dari pendidikan kesehatan.

\section{METODE PENELITIAN}

Penelitian ini merupakan penelitian jenis correlational dengan design cross sectional yang dilakukan di Ruang Poli Saraf RSUD Kota Kotamobagu pada bulan Juni 2020. Populasi target penelitian ini yaitu 30 penderita hipertensi yang melakukan kunjungan sejak bulan Oktober 2019. Sampel penelitian adalah 30 penderita Hipertensi yang dipilih dengan teknik

non-probability sampling yaitu total sampling.

Instrumen pengumpulan data merupakan alat bantu yang digunakan oleh peneliti untuk kegiatan penelitian pengumpulan data dalam kegiatannya untuk mengumpulkan data agar menjadi

Uji korelasi yang digunakan dalam penelitian ini yaitu uji Chi Square karena data berbentuk katagorik. Penelitian ini telah mendapatkan surat keterangan layak etik dari Komisi Etik Penelitian Program studi S1 Keperawatan Stikes Graha Medika Kotamobagu.

\section{HASIL PENELITIAN}

Tabel 1 .

Karakteristik Responden Penelitian

\begin{tabular}{cccc}
\hline Variabel & Kategori & $\mathrm{N}$ & $\%$ \\
Umur & $35-60$ & 20 & 66,7 \\
& $60-80$ & 10 & 33,3 \\
\multirow{2}{*}{ Jenis Kelamin } & Laki-laki & 15 & 50 \\
\multirow{2}{*}{ Pekerjaan } & Perempuan & 15 & 50 \\
& Petani & 22 & 73,3 \\
& IRT & 26 & 81,2 \\
& ASN & 2 & 6,7 \\
& Swasta & 6 & 20 \\
\hline
\end{tabular}

Tabel 1 menunjukkan karakteristik responden penelitian. menunjukkan bahwa data dalam penelitian jenis kelamin laki laki 15 orang persen $50 \%$ dan perempuan 15 orang $50 \%$. Umur responden menunjukkan bahwa data dalam penelitian ini, umur 35-60 20 orang $66,7 \%$ umur $60-8010$ orang $(33,3 \%)$ bahwa data dalam penelitian tidak bekerja/IRT 22 orang 73,3\%, PNS 2 orang $6.7 \%$ pegawai swasta 6 orang $(20 \%)$ 
Tabel 2.

Pengetahuan Responden

\begin{tabular}{lcc}
\hline \multicolumn{1}{c}{ Pengetahuan } & Pengetahuan Responden & \% \\
& & \\
\hline Kurang Baik & 11 & 36,7 \\
\multirow{2}{*}{ Baik } & 19 & 63,3 \\
\hline Total & $\mathbf{3 0}$ & $\mathbf{1 0 0}$ \\
\hline
\end{tabular}

Pada tabel 2 di atas, 11 Responden $(36,7 \%)$ memiliki pengetahuan kurang baik; 19 Responden $(63,3 \%)$ memiliki pengetahuan baik.

Tabel 3.

\begin{tabular}{lcc}
\multicolumn{1}{c}{ Sikap } & Sikap & \\
\hline Kurang Baik & N & \% \\
Baik & 11 & 63,3 \\
\hline Total & 19 & $\mathbf{1 0 0}$
\end{tabular}

Berdasarkan tabel 5.6. di atas menunjukkan bahwa yang memiliki sikap yang kurang baik sebanyak 11 orang $(36,7 \%)$ dan memiliki sikap baik sebanyak 19 responden $(63,3 \%)$ dari total 30 Responden.

Tabel 4

Hasil Analisis Chi Square

\begin{tabular}{|c|c|c|c|c|c|c|c|c|}
\hline \multicolumn{9}{|c|}{$\begin{array}{l}\text { Hasil Analisis Chi Square } \\
\text { Upaya Pencegahan Stroke }\end{array}$} \\
\hline & & \multicolumn{2}{|c|}{ Kurang Baik } & \multicolumn{2}{|c|}{ Baik } & \multicolumn{2}{|c|}{ Total } & \multirow[t]{2}{*}{$P$ Value } \\
\hline & & $\mathrm{N}$ & $\%$ & $\mathrm{n}$ & $\%$ & $\mathrm{~N}$ & $\%$ & \\
\hline \multirow[t]{2}{*}{ Pengetahuan } & Kurang Baik & 9 & 30 & 2 & 6,7 & 11 & 36,7 & \\
\hline & Baik & 2 & 6,7 & 17 & 56,7 & 19 & 63,3 & 0,000 \\
\hline Total & & 23 & 71.9 & 9 & 28.1 & 32 & 100 & \\
\hline
\end{tabular}

Berdasarkan Tabel 4 di atas menunjukkan bahwa pengetahuan kurang baik dengan upaya pencegahan stroke kurang baik adalah 9 responden, baik 2 responden dan hasil untuk pengetahuan baik dengan upaya pencegahan baik 17 , tidak baik 2 responden dengan jumlah keseluruhan adalah 30 responden dengan nilai $(\mathrm{p}<\mathrm{a}$ $=0,000$ )

Hasil analisis hubungan pengetahuan dengan upaya pencegahan stroke di Poli Saraf RSUD Kota Kotamobagu menggunakan Uji ChiSquare dengan tingkat kepercayaan $95 \%$ $(\mathrm{a}=0,000)$ didapatkan hasil $\mathrm{P}$ value adalah 0,000 dengan demikian $(0,000<0,005)$, ini berarti Ho di tolak dan Ha di terima, sehingga kesimpulannya yaitu ada hubungan pengetahuan dengan upaya pencegahan stroke di Poli Saraf RSUD Kota Kotamobagu. 
Tabel 5

Hasil Analisis Chi Square

Upaya Pencegahan Stroke

\begin{tabular}{ccccccccc}
\hline & & \multicolumn{2}{c}{ Kurang Baik } & \multicolumn{2}{c}{ Baik } & \multicolumn{2}{c}{ Total } & p value \\
\hline & & $\mathrm{N}$ & $\%$ & $\mathrm{n}$ & $\%$ & $\mathrm{~N}$ & $\%$ & \\
\hline Sikap & Kurang Baik & 11 & 36,7 & 0 & 0 & 11 & 36,7 & \\
\hline Total & Baik & 0 & 0 & 19 & 63,3 & 19 & 63,3 & 0,000 \\
\hline & & 11 & 36,7 & 19 & 63,3 & 30 & 100 & \\
\hline
\end{tabular}

Berdasarkan Tabel 5 di atas menunjukkan bahwa sikap kurang baik dengan upaya pencegahan stroke kurang baik adalah 11 responden, baik 0 responden dan hasil untuk sikap baik dengan upaya pencegahan baik 19 , tidak baik 0 responden dengan jumlah keseluruhan adalah 30 responden dengan nilai $(\mathrm{p}<\mathrm{a}=0,000)$

Hasil analisis hubungan sikap dengan upaya pencegahan stroke di Poli

\section{PEMBAHASAN}

Hasil penelitian ini menunjukkan bahwa dari data 30 responden di Poli Saraf RSUD Kota Kotamobagu diperoleh data untuk umur responden, yang berusia 30-60 tahun yaitu 20 responden $(66,7)$ dan 60-80 memiliki 10 responden $33,3 \%$. Kemudian berdasarkan pengetahuan pada tabel 2 menunjukkan bahwa kategori data terbanyak untuk pengetahuan baik adalah 19 responden $(63,3 \%)$ dan kriteria kurang baik 11 responden $(36,7 \%)$. Faktor utama yang mempengaruhi pengetahuan adalah umur, pendidikan, pengalaman, pekerjaan dan jenis kelamin. Kemudian berdasarkan tabel 5.5 menunjukkan bahwa kategori sikap terbanyak adalah baik dengan 19 responden $(63.3 \%)$ dan sikap kurang baik sebanyak 11 responden $(36.7 \%)$. Faktor utama yang mempengaruhi sikap adalah fisiologis,
Saraf RSUD Kota Kotamobagu menggunakan Uji Chi-Square dengan tingkat kepercayaan 95\% ( $a=0,000)$ didapatkan hasil $p$ value adalah 0,000 dengan demikian $(0,000<0,005)$, ini berarti Ho di tolak dan $\mathrm{Ha}$ di terima, sehingga kesimpulannya yaitu ada hubungan sikap dengan upaya pencegahan stroke di Poli Saraf RSUD Kota Kotamobagu.

komunikasi sosial, pengalaman, usia dan kesehatan.

Responden yang datang berkunjung di Poli Saraf RSUD Kota Kotamobagu sebagian besar penderita Hipertensi Grade II yang diperoleh dari gaya hidup serta faktor-faktor lainnya yang menunjang terjadinya Hipertensi. Hasil penelitian ini juga menyatakan bahwa penderita Hipertensi Grade II beresiko tinggi terkena stroke seperti yang disampaikan dalam penelitian oleh (Langingi A. R., 2017). Hasil penelitian ini juga sejalan dengan penelitian (Damanik, 2018) menyatakan ketidaktahuan responden terhadap penyakit stroke, sehingga pemahaman untuk melakukanperilaku pencegahan stroke pada penderita hipertensi juga buruk. Hal ini menunjukkan bahwa pengetahuan juga menentukan bagi penderita Hipertensi agar terlebih dahulu 
mengenali penyakitnya sehingga pencegahan komplikasi dapat dilakukan.

Hasil penelitian ini juga menyatakan bahwa pengetahuan penderita hipertensi perlu ditingkatkan dengan cara meningkatkan jumlah kehadiran berobat penderita agar semakin diberikan pendidikan kesehatan yang merupakan modal pengetahuan tentang pencegahan stroke, terlebih kelompok khusus lansia yang sangat rentan dengan stroke

Demikian juga dengan hasil penelitian yang dilakukan oleh (Safitri, Agustin, \& Murhayati, 2019) yang menyatakan bahwa terdapat hubungan pegetahuan dengan motivasi pencegahan stroke penderita Hipertensi di Kelurahan Jebres Surakarta. Seorang individu dengan tingkat pendidikan yang tinggi akan mempengaruhi cara pola pikir dan pemahaman tentang konsep penyakit dan kesehatan dalam hal ini pencegahan tentang pencegahan stroke. Seseorang yang memiliki pengetahuan baik maka juga akan berkontribusi dalam kuatnya motivasi seseorang.

Penelitian lain yang mendukung hasil penelitian ini yang menyatakan bahwa pengetahuan tentang hipertensi berhubungan dengan sikap pencegahan komplikasi hipertensi. Pengetahuan yang baik menentukan sikap penderita Hipertensi dalam mencegah komplikasi akibat hipertensi (Manullang, 2019). Pengetahuan responden umumnya baik yang ditandai dengan adanya upaya responden untuk mengontrol hipertensi dengan kepatuhan diet rendah garam (Mapagerang, Alimin, \& Anita, 2018).kepatuhan diet rendah garam penderita hipertensi akan membantu menurunkan derajat hipertensi bahkan resiko komplikasi hipertensi.

Upaya pencegahan stroke dari responden hipertensi dalam penelitian ini juga dinilai baik, disebabkan karena perubahan gaya hidup responden dari perilaku hidup yang tidak sehat menjadi perilaku sehat menjadi bagian dari upaya pencegahan stroke.

Hasil penelitian ini juga menyatakan bahwa sikap penderita Hipertensi juga berhubungan dengan upaya pencegahan stroke penderita hipertensi di Poli Saraf RSUD Kota Kotamobagu. Terdapat hubungan sikap dengan upaya pencegahan stroke penderita hipertensi dikarenakan sikap dari 30 responden sebagian besar memiliki sikap yang baik dalam pencegahan stroke. Perilaku merupakan suatu respon atau reaksi seseorang terhadap stimulus (rangasangan dari luar). Perilaku kesehatan (health behavior) adalah respon seseorang terhadap stimulus atau objek yang berkaitan dengan sehat-sakit, penyakit dan faktor-faktor yang mempengaruhi kesehatan, seperti lingkungan, makanan, minuman dan pelayanan kesehatan. Hasil penelitian ini juga sejalan dengan teori yang menyatakan bahwa perilaku yang sejalan dengan pengetahuan akan menunjukan perilaku yang baik dan bertahan lama, sedangkan perilaku yang tidak sejalan dengan pengetahuan akan menunjukan perilaku yang kurang baik dan tidak akan bertahan lama. Sebelum seorang berperilaku baru, ia harus memiliki pengetahuan terlebih dahulu tentang arti atau manfaat perilaku tersebut bagi dirinya karena faktor pengetahuan merupakan faktor dominan yang sangat penting untuk terbentuknya perilaku seseorang. Teori mengemukakan pengetahuan dan kognitif merupakan domain yang penting terbentuknya (Notoatmodjo, 2012).

Pengetahuan dan sikap memiliki hubungan atau peluang mengendalikan hipertensi. Sikap yang dinilai baik dikarenakan pasien hipertensi berusaha menurunkan tekanan darah dengan mengkonsumsi obat anti hipertensi, berolahraga untuk menurunkan tekanan darah serta rajin memeriksakan 
kesehatan kepada dokter. Sikap belum merupakan suatu tindakan atau aktifitas, akan tetapi merupakan predisposisi tindakan suatu perilaku. Suatu sikap pada diri individu belum tentu terwujud dalam suatu tindakan nyata. sikap tidak dapat langsung dilihat, tetapi hanya dapat ditafsirkan terlebih dahulu dari

\section{KESIMPULAN}

Terdapat hubungan sikap dengan upaya pencegahan stroke pada pasien hipertensi di Poli Saraf RSUD Kota Kotamobagu; Pengetahuan pasien hipertensi di Poli Saraf RSUD Kota Kotamobagu pada umumnya memiliki pengetahuan baik; Sikap pasien hipertensi di Poli Saraf RSUD Kota Kotamobagu pada umumnya memiliki

\section{SARAN}

Dari penelitian ini dapat menjadi referensi dan daftar pustaka untuk peneliti selanjutnya diharapkan dapat melanjutkan penelitian dengan jumlah sampel yang lebih banyak lagi dengan metodelogi lain agar melakukan penelitian lebih mendalam terkait derajat hipertensi agar bisa dijadikan sumber

\section{DAFTAR PUSTAKA}

Abdul, A., Damanik, R., \& Imawati, S. (2016). Hubungan Kejadian Efusi Pleura Pada Pasien Gagal Jantung Kongestif Berdasarkan Foto Thoraks Di RSUP Dr Kariadi. Jurnal Kedokteran Diponegoro, 393-402.

Damanik, H. (2018). HUBUNGAN PENGETAHUAN PENDERITA HIPERTENSI TENTANG STROKE DENGAN PERILAKU PENCEGAHAN STROKE DI PUSKESMAS HELVETIA MEDAN. Jurnal Keperawatan Priority, 73-84. perilaku tertutup. Dengan demikian sikap merupakan salah satu faktor yang sangat berpengaruh terhadap nilai kesehatan individu serta dapat menentukan cara pengendalian yang tepat untuk penderita hipertensi (Sunaryo, 2014).

sikap baik; Terdapat hubungan pengetahuan dengan upaya pencegahan stroke pada pasien hipertensi di Poli Saraf RSUD Kota Kotamobagu; Terdapat hubungan sikap dengan upaya pencegahan stroke pada pasien hipertensi di Poli Saraf RSUD Kota Kotamobagu;

pengetahuan baru, meningkatkan jumlah kunjungan ke dokter serta konsultasi tentang pencegahan komplikasi yang beresiko timbul nantinya; peningkatan penyuluhan kesehatan dari petugas kesehatan di Poli Saraf RSUD Kota Kotamobagu untuk menekan terjadinya komplikasi hipertensi pada penderita.

\section{Langingi, A. R. (2017). CORRELATION BETWEEN OBESITY WITH HYPERTENSION. Manado Health Polytechnic 1st International Conference. (pp. 518-523). Manado: Manado Health Polytechnic.}

Langingi, A. R., Sudirman, \& Watung, G. I. (2020). Analisis Faktor Perilaku Dan Jarak Fasilitaskesehatan Terhadap Pemanfaatan Posyandu Lansia Hipertensi Di Desa Muntoi 
Kecamatan Passi Barat. MTPHJournal, 121-126.

Manullang, K. F. (2019). Hubungan Tingkat Pengetahuan Tentang Hipertensi Dengan Sikap Dalam Pencegahan Komplikasi Hipertensi Di Ruang Poli. SCIENTIFIC PAPER, 1-27.

Mapagerang, R., Alimin, M., \& Anita. (2018). Hubungan Pengetahuan Dan Sikap Pada Penderita Hipertensi Dengan Kontrol Diet Rendah Garam. JIKP@JURNAL
ILMIAH

KESEHATAN PENCERA, 37-44.

Notoatmodjo. (2012). Promosi kesehatan dan perilaku Kesehatan. Jakarta: Rineka Cipta.

Safitri, W., Agustin, W. R., \& Murhayati, A. (2019). Pengetahuan Dengan Motivasi Pencegahan Stroke Pada Penderita Hipertensi. Adi Husada Nursing Journal, 45-51.

Sunaryo. (2014). Psikologi untuk Keperawatan. Jakarta: EGC. 